\title{
A RELAÇÃO TEORIA-PRÁTICA NA EDUCAÇÃO FÍSICA ESCOLAR: \\ DESDOBRAMENTOS PARA PENSAR UM “PROGRAMA MÍNIMO”
}

DOI 105902/0102830815956

Artigo Convidado

\author{
Luciano de Almeida \\ UNIJUÍ \\ luciano.almeida@iffarroupilha.edu.br \\ Paulo Evaldo Fensterseifer \\ UNIJUÍ \\ fenster@unijui.edu.br
}

RESUMO: O objetivo deste artigo é refletir acerca da difícil e complexa relação teoriaprática na Educação Física. Como pano de fundo, traz elementos de algumas proposições realizadas em escolas públicas, materializadas na tentativa de construção de uma proposta de trabalho ou "programa mínimo" para a Educação Física, para além de um simples "exercitar-se", vislumbrando a construção de um saber a ser desenvolvido ao longo dos anos escolares em termos de criticidade, complexidade e continuidade. Para isso, consideramos a relação teoria-prática condição indispensável para pensarmos a Educação Física no contexto escolar e valorizarmos a experiência e o saber da experiência como forma de conhecer, fazer e conhecer com esse fazer. Essa experiência acontece no diálogo constante e sempre renovado com a ação interventiva, outros professores e as obras que tratam sobre o tema. Concluímos que a construção dessa proposta nos permite (re)construir e reinventar nossa profissão com autoria, "experimentando" as possibilidades de encontrar algumas respostas para os desafios que hoje se colocam para a Educação Física, através de nossa ação interventiva e reflexiva.

Palavras-chave: Educação Física. Contexto escolar. Experiência. Proposta de trabalho. 


\section{Notas iniciais...}

Mesmo antes de nossa inserção no contexto de trabalho, vivemos as angústias, expectativas e incertezas de conseguir justificar nossas ações na escola. Ficamos confusos devido à diversidade de temas historicamente produzidos e incorporados pela Educação Física: esportes, jogos, lutas, dança, acrobacias, atividade física de aventura na natureza..., temas esses que entendemos devam ser abordados em nossas aulas. Porém, o que acontece, via de regra, é que somos absorvidos pelo contexto escolar e começamos a reproduzir o que denunciávamos enquanto acadêmicos de Educação Física, reduzindo nossas aulas ao plano de atividades com um fim em si mesmas.

Uma alternativa possível para enfrentarmos esse processo de "reaprender a ver a Educação Física" pode estar na construção de um "programa mínimo" (KUNZ, 2000, p. $150)$, que nos permita "pensar um saber que se desenvolve ao longo dos anos escolares em complexidade e criticidade" (FENSTERSEIFER; GONZÁLEZ, 2010, p. 13).

Desde 2004, vimos tentando construir uma proposta de trabalho para a Educação Física nos diferentes contextos em que atuamos como professores de Educação Física'. Nesses anos estabelecemos um diálogo constante com nossa própria intervenção, com outros colegas e com as obras que tratam sobre o tema. Percebemos esse diálogo como elemento fundamental para (re)pensar a relação dicotômica teoria-prática, presente em todas as áreas do conhecimento, em especial na Educação Física, pelo seu estreito vínculo com a prática. A relação teoria-prática é condição indispensável para pensarmos a Educação Física, pois a solução para os problemas, como lembra Hannah Arendt (2002), depende dos envolvidos. Nesse sentido, não podemos ser espectadores ou "aplicadores" de soluções pensadas por outros, temos que ser os protagonistas para que as mudanças de sentido aconteçam no contexto em que atuamos. Como professores não podemos simplesmente aplicar "teoria" na "prática" e, sim, (re)construir/(re)inventar nossa prática "com referência

\footnotetext{
${ }^{1}$ A elaboração deste artigo se estabeleceu no diálogo constante dos autores durante anos de reflexão, dedicados a discutir questões relacionadas à Educação Física no contexto escolar. É nesse diálogo "que vivemos a irritação causada pela pergunta do outro e o risco de ver nossas supostas certezas postas em xeque" (FLICKINGER, 2010, p. 6). No decorrer deste texto, um dos autores trará elementos de sua ação interventiva para o diálogo.
} 
em ações/experiências e em reflexões/teorias. É fundamental que essa apropriação de teorias se dê de forma autônoma e crítica, portanto, como ação de um sujeito, de um autor" (BRACHT; CAPARROZ, 2007, p. 27).

Enfatizamos o ano de 2004 como o início da tentativa de construção de uma proposta para a Educação Física e, também, como um marco de ruptura paradigmática de nossa própria intervenção, tendo em vista os anos dedicados à ação interventiva em escolas públicas. Desde nossa inserção no universo profissional fizemos diferentes experiências, com jogos, esportes, ginásticas, atividades rítmicas e expressivas, atividade física e saúde... temas esses que ficavam expressos no plano de atividades, sem um grau de complexidade e continuidade.

Nesses anos de intervenção e de formação permanente no próprio espaço de trabalho, percebemos que nossas expectativas ainda não foram atendidas, o que não deixa de ser positivo, pois encontramos alento na noção de experiência proposta por Gadamer (2008), principalmente em Verdade e Método, em que este afirma que "a experiência pressupõe necessariamente que se frustrem muitas expectativas, pois somente é adquirida através disso" (p. 465). Portanto, compreender a noção de experiência pode nos proporcionar um saber mais amplo, não um saber concludente, próprio das ciências da natureza, pelo uso metódico da razão, mas um saber melhor, "não somente sobre si mesmo mas também sobre aquilo que antes se acreditava saber, isto é, sobre o universal" (GADAMER, 2008, p. 462).

Nas palavras de Gadamer, percebemos o caráter de imprevisibilidade da experiência, algo que soa ainda como um escândalo para a tradição educativa. Imprevisibilidade porque estamos expostos aos riscos e às incertezas que a experiência educativa proporciona. Não podemos, porém, garantir um modo seguro de atuar, porque não podemos transpor mecanicamente modelos definidos a priori para a realidade social em que se dá nossa prática pedagógica, pois isso "geralmente leva à cristalização desta e à falta de sentido para ela" (BRACHT; CAPARROZ, 2007, p. 33).

Retomando a ideia inicial de ingresso no universo do trabalho, percebemos que a formação acadêmica nos proporciona uma experiência que "só se atualiza nas observações [vivências] individuais. Não se pode conhecê-la numa universalidade prévia" (GADAMER, 
2008, p. 260). Isso geralmente acontece ao tentarmos universalizar uma experiência proposta na graduação para o universo do trabalho, sem considerar o elemento histórico da própria experiência.

Nesse sentido, a experiência assume um caráter de experimento, tanto nas ciências da natureza, através de seu aparato metodológico, quanto nas ciências do espírito (humanas), pelo método da crítica histórica, em que a objetividade é garantida "pelo fato de as experiências feitas ali poderem ser repetidas por qualquer pessoa" (GADAMER, 2008, p. 454). Enquanto, na primeira, os experimentos devem ser passíveis de verificação, na segunda, o procedimento completo deve ser passível de controle. Nesse sentido, na ciência "não pode restar espaço para a historicidade da experiência" (ibidem).

Essas determinações metodológicas passíveis de verificação e controle "costumam reduzir o espaço da experiência, em que aquele que aprende deve entregar-se à nova situação, aceitando o risco das incertezas" (HERMANN, 2002, p. 85). Como modernos, estamos acostumados a tentar controlar as circunstâncias em que o processo educativo ocorre. Ao fazermos isso, reduzimos a experiência educativa a um experimento, controlável, manipulável, numa relação sujeito-objeto, no sentido do sujeito que domina o objeto, próprios de uma racionalidade instrumental.

A experiência educativa possui um caráter de imprevisibilidade e de abertura a novas experiências, "exige a exposição ao risco, às situações abertas e inesperadas, coincidindo com a impossibilidade de assegurar a tais práticas educativas uma estrutura estável, que garanta o êxito da ação interventiva" (idem, p. 86). Percebemos essa estrutura "instável” em nossa própria intervenção profissional ao tentarmos "implementar" nossa proposta de trabalho para a Educação Física no espaço escolar. Essa experiência nos permite encontrar os limites de nossa própria intervenção e, ao mesmo tempo, vislumbrar as possibilidades de justificá-la no contexto em que atuamos.

\section{O caráter de imprevisibilidade de "nossa" proposta de trabalho}

Em nossa proposta de trabalho, temos feito um esforço de pensar a Educação Física como componente curricular articulado a um projeto educacional, pautado na ideia de “leitura do mundo" (FENSTERSEIFER; GONZÁLEZ, 2010, p. 12). Esse esforço encontra 
uma de suas possibilidades quando interpretamos nossa ação educativa como uma reflexão hermenêutica, isso implica que, "na compreensão de algo ou alguém, produz-se uma autocrítica" (HERMANN, 2002, p. 85). Essa autocrítica não acontece no vazio, sem referências. Ela ocorre quando submetemos nossas posições (intervenção) à crítica de nossos pares, "sem a qual nossas verdades não passam de nossas verdades, necessárias mas não suficientes para enfrentar o tamanho dos desafios que hoje se colocam para a EF" (FENSTERSEIFER; GONZÁLEZ, 2007, p. 37).

É nesse sentido que passamos a expor neste momento algumas de "nossas" verdades, materializadas no nosso desejo de contribuir para legitimar a Educação Física no contexto escolar a partir da construção de "nossa" proposta de trabalho². Como já mencionado anteriormente, a construção desta proposta começou a ser elaborada no ano de 2004, com o intuito de promover uma mudança em nossa ação pedagógica, tendo em vista que não conseguíamos sustentar discursivamente nossas próprias intervenções no contexto escolar.

Essa construção foi possibilitada a partir das obras e concepções de diferentes autores que tratam sobre as especificidades da Educação Física, Escola, contexto escolar, experiência, hermenêutica..., contribuindo, dessa forma, para sua elaboração. Entendemos que "um" dos principais objetivos da Educação Física, é o de oportunizar aos alunos a apropriação das diferentes manifestações da cultura corporal de movimento em benefício da construção de um corpo de conhecimentos que possam auxiliá-los a praticar, analisar, compreender, de maneira crítica e sensível, os temas/conteúdos produzidos e incorporados pela Educação Física ao longo de sua história em benefício de sua constituição humana, de intervenção no mundo comum, buscando construir as condições de vida desejáveis. Como alcançar esse objetivo tão amplo, ao longo dos anos escolares, ao reduzir nossas aulas ao plano de atividades, com um fim em si mesmas?

$\mathrm{Na}$ tentativa de esboçar um entendimento sobre essa questão, estabelecemos alguns critérios para selecionar os temas/conteúdos historicamente incorporados pela Educação Física como referência para consolidar nosso trabalho, no intuito de justificar nossa

\footnotetext{
${ }^{2}$ Pontuaremos algumas questões que achamos interessantes para a presente discussão, trazendo os elementos constitutivos dessa proposta de trabalho e ainda algumas experiências com sua a implementação, que vão desde sua apresentação aos alunos até o planejamento participativo (escolha dos "conteúdos"), dentro dos temas propostos.
} 
intervenção na escola. Tradicionalmente o esporte é um dos, senão o único, tema abordado nas aulas de Educação Física na escola, a ponto de ser confundido com a própria Educação Física.

Não estamos advogando contra o esporte, mas considerando as possibilidades de tratálo pedagogicamente na Educação Física, para além de uma monocultura (principalmente futebolística) de esporte, e, ainda, vendo-o como "um" dos temas/conteúdos da Educação Física escolar, mas não o único. Se não oportunizarmos aos alunos a "chance de experimentar boa parte do leque de possibilidades de movimento sistematizadas pelos seres humanos ao longo de vários anos", eles estarão perdendo "parte do acervo cultural da humanidade e uma possibilidade singular de perceber o mundo e de perceber-se" (FENSTERSEIFER; GONZÁLEZ, 2010, p. 17).

É nesse sentido que há uma necessidade de abordar a pluralidade de manifestações de movimento/práticas corporais na Educação Física na escola. Como ponto de partida, adotamos uma classificação, proposta por González (2003; 2006), para construir o nosso "programa mínimo" para a Educação Física e ampliar o espectro do conteúdo "esporte”. Essa classificação nos auxilia a pensar nas diferentes demandas exigidas em cada modalidade esportiva, além de permitir localizar os diferentes tipos de esportes, pois se estabelece em função de quatro categorias: “a) a relação com o adversário; b) a lógica de comparação de desempenho; c) as possibilidades de cooperação; e d) as características do ambiente físico onde se realiza a prática esportiva".

Com base em González (2003; 2006) e em diferentes obras/autores que discutem as especificidades da Educação Física, dentre os quais destacamos Betti (1994, 1996), Bracht (2003), Coletivo de Autores (1992) e os Parâmetros Curriculares Nacionais (BRASIL, 1998) ${ }^{3}$, elaboramos uma proposta de intervenção por nós denominada de "Mapa de Trabalho".

${ }^{3}$ Cabe destacar que essas referências foram utilizadas na construção da "primeira" versão da proposta de trabalho (2004) e, depois, que outras foram incorporadas para tomar lugar no "diálogo" com nossa intervenção, dentre as quais destacamos: Kunz (2000, 2001); Fensterseifer e González (2007, 2009, 2010) e González e Fraga $(2009,2012)$. 


\begin{tabular}{|c|c|c|c|c|c|c|c|c|c|c|c|c|c|c|c|c|c|c|}
\hline \multicolumn{19}{|c|}{ CULTURA CORPORAL DE MOVIMENTO } \\
\hline & & & & & & & rátic & is Corp & rais & Sistem & atizadas & & & & & & & \\
\hline \multirow[b]{3}{*}{ Séries } & \multicolumn{7}{|c|}{ Esportes } & \multirow{3}{*}{ 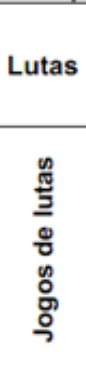 } & \multirow{2}{*}{\multicolumn{3}{|c|}{ Ginástica }} & \multirow{2}{*}{\multicolumn{2}{|c|}{$\begin{array}{c}\text { Práticas } \\
\text { corporais } \\
\text { junto à } \\
\text { natureza }\end{array}$}} & \multirow{2}{*}{\multicolumn{2}{|c|}{$\begin{array}{c}\text { Práticas } \\
\text { corporais } \\
\text { expressivas }\end{array}$}} & \multirow{3}{*}{ 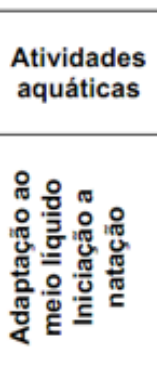 } & \multirow{2}{*}{\multicolumn{2}{|c|}{$\begin{array}{l}\text { Representações } \\
\text { sociais CCM }\end{array}$}} \\
\hline & \multicolumn{4}{|c|}{ Com interação } & \multicolumn{3}{|c|}{ Sem interação } & & & & & & & & & & & \\
\hline & 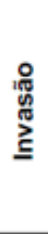 & 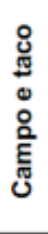 & 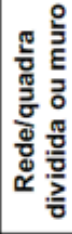 & 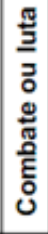 & 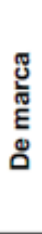 & 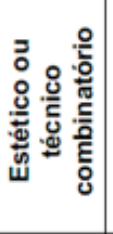 & 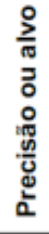 & & 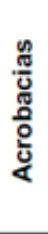 & 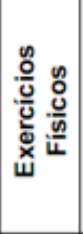 & 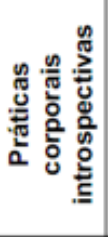 & 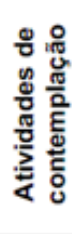 & 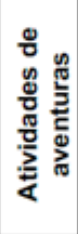 & 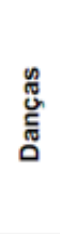 & 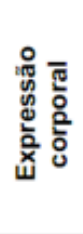 & & 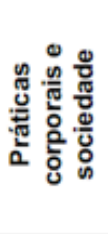 & 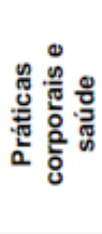 \\
\hline $1^{\circ}$ & & & & & & & & & & & & & & & & & & \\
\hline $2^{\circ}$ & & & & & & & & & & & & & & & & & & \\
\hline $3^{\circ}$ & & & & & & & & & & & & & & & & & & \\
\hline
\end{tabular}

Figura 1. "Mapa de Trabalho" (para o ensino médio). Adaptado de González e Fraga (2009, 2012).

Esse "Mapa de Trabalho" contempla alguns "conteúdos"4 que pensamos devam fazer parte de um programa de ensino para a Educação Física escolar, se entendermos que é de sua responsabilidade a tematização da cultura corporal de movimento ${ }^{5}$. Os conteúdos ${ }^{6}$ a que nos referimos aparecem, nesse desenho, de maneira compartimentada e incompleta, tendo em vista que poderiam ser incluídos mais elementos nas categorias apresentadas. Mas é preciso explicitar que muitos desses conteúdos podem ser tratados de diferentes formas: o tema lutas pode fazer referência ao esporte institucionalizado, com regras específicas regulamentadas por federações e confederações, como é o caso do Judô, por exemplo. O mesmo tema pode também ser adotado para fazer referência a dois adversários que disputam a conquista da bola em um jogo de futsal, ou, ainda, um jogo de luta em que dois oponentes ou mais tentam sobrepujar seu(s) adversário(s) em uma queda-de-braço ou de cabo-de-guerra (COLETIVO DE AUTORES, 1992).

\footnotetext{
${ }^{4} \mathrm{Na}$ tentativa de esclarecer o conceito, Darido (2001, p. 5), com base em Coll e outros define conteúdo como "uma seleção de formas ou saberes culturais, conceitos, explicações, raciocínios, habilidades, linguagens, valores, crenças, sentimentos, atitudes, interesses, modelos de conduta, etc., cuja assimilação é considerada essencial para que se produza um desenvolvimento e uma socialização adequada ao aluno".

${ }^{5}$ De acordo com Bracht (2004, p. 4), as manifestações da cultura corporal de movimento "significam (no sentido de conferir significado) historicamente a corporeidade e a movimentalidade - são expressões concretas, históricas, modos de viver, de experenciar, de entender o corpo e o movimento e as nossas relações com o contexto - nós construímos, conformamos, confirmamos e reformamos sentidos e significados nas práticas corporais".

${ }^{6}$ Entendemos que o saber escolar materializa-se nos "conteúdos", na contribuição das especificidades de cada componente curricular (muitas vezes integrada de forma interdisciplinar), pois, de acordo com Sacristán (2000), sem conteúdo "não há ensino, qualquer projeto educativo acaba se concretizando na aspiração de conseguir alguns efeitos nos sujeitos que se educam. Referindo-se estas afirmações ao tratamento científico do ensino, pode-se dizer que sem formalizar os problemas relativos aos conteúdos não existe discurso rigoroso nem científico sobre o ensino, porque estaríamos falando de uma atividade vazia ou com significado à margem do para que serve" (p. 120).
} 
Em nossa intervenção profissional, temos mantido um estreito vínculo entre teoria e prática, elaborando assim uma prática reflexiva em que os alunos também são partícipes da construção do seu próprio processo de ensino e aprendizagem ${ }^{7}$. Nessa relação pedagógica potencializamos a oportunidade de o educando e o educador entregarem-se a uma situação aberta, em uma relação de diálogo que, "além de trabalhar determinados conteúdos, se processa como relação social; ou seja, como relação de desafio, no sentido de fazer do vir ao encontro do outro o campo de aprendizagem intersubjetivo e, por isso mesmo, éticomoral" (FLICKINGER, 2010, p. 7).

Essa proposta vem nos acompanhando e auxiliando a orientar nossa ação interventiva no decorrer desses anos, nos diferentes contextos em que atuamos. Chamamos a atenção para o fato de que esses conteúdos necessitam ser explicitados e reinventados a cada novo coletivo e em cada turma de alunos em que nos inserimos, para que compartilhem da construção de conceitos, "construção sempre ligada às experiências de que, em comum, participam" (MARQUES, 1992, p. 562).

A cada nova turma em que nossa proposta é apresentada, experienciamos uma relação de tensão permanente, nem sempre previsível (ou quase sempre imprevisível), não definida a priori, mas aberta ao diálogo, no qual se dá sempre, de novo, uma nova experiência com a construção de conceitos, a reconstrução do imaginário acerca da Educação Física e a escolha dos elementos da cultura corporal de movimento que farão parte de sua aprendizagem durante um ano letivo. Não há como pensar uma mesma aula para ser "aplicada" a várias turmas e contextos diferentes, isso seria desconsiderar a condição humana de nossos alunos, que "impõe um caráter irrestritamente singular às nossas aulas" (BRACHT; CAPARROZ, 2007, p. 29).

Ao tratarmos dos diferentes temas/conteúdos que compõem o universo do movimento humano/práticas corporais a serem tematizadas/vivenciadas durante o ano letivo, encontramos certo comportamento de oposição de nossos alunos a uma nova proposição, pois suas experiências/vivências de movimento em seus anos de escolarização resumiamse à prática de algumas atividades esportivas.

\footnotetext{
${ }^{7}$ Ao oportunizarmos aos alunos a participação na construção de seu processo de ensino e aprendizagem, atendemos, em parte, a um dos desafios que se colocam à escola, a saber, "facilitar e estimular a participação ativa e crítica dos alunos nas diferentes tarefas que se desenvolvem na aula e que constituem o modo de viver da comunidade democrática da aprendizagem" (PÉREZ-GÓMEZ, 1998, p. 26).
} 
Esse comportamento de oposição é resolvido no diálogo, pelo qual nos vemos (educando e educador), "desafiados a reconsiderar nossas próprias convicções e supostas certezas" (FLICKINGER, 2010, p. 43). Essa experiência do diálogo pressupõe um espaço único em que "pode se dar o convencimento necessário a respeito dos conteúdos da aprendizagem, e o aluno pode realizar sua experiência" (HERMANN, 2002, p. 85). Esse convencimento passa por uma ruptura paradigmática com a tradição esportiva da Educação Física, pois "tratamos de uma dimensão [mais ampla] da cultura e que temos uma responsabilidade com o conhecimento produzido em torno dela, algo, portanto que vai muito além do 'exercitarse"” (FENSTERSEIFER; GONZÁLEZ, 2010, p. 12).

O comportamento de oposição, referido anteriormente, encontra-se expresso na fala de Rafael $^{8}$, em uma aula de Educação Física em que a proposta foi apresentada: "O que queremos com isso professor? Vamos jogar bola!". A apresentação se dá na forma de diálogo aberto, quando acontece a tentativa de convencimento quanto às possibilidades de nos apropriarmos de um universo mais amplo, das diferentes manifestações de movimento/ práticas corporais com a intencionalidade de atingir alguns propósitos da instituição escolar e da própria Educação Física. Em avaliação realizada no final desse mesmo ano (2005), sobre os aspectos positivos e negativos de nossa proposta de trabalho, o mesmo aluno escreve: "O tempo foi curto para fazer todas as atividades planejadas. Espero que no ano que vem aprendemos coisas novas".

A partir dessa e de outras experiências que temos realizado em diferentes contextos, podemos dizer que estamos conseguindo abordar diferentes elementos da cultura (corporal de movimento), para além das atividades esportivas, como mera reprodução irrefletida de um "fazer", atendendo ao disposto de que, na recente tradição da Educação Física, fomos desafiados a construir um "saber" com esse "fazer". Porém, é preciso ter cuidado para elaborar um saber realmente articulado "com" esse fazer, pois, de outra forma, corremos o risco de cometer alguns equívocos e transformar a Educação Física em um discurso sobre a cultura corporal de movimento (BETTI, 1994), ou, ainda, como reafirma Bracht (2003), não podemos transformá-la num discurso sobre o movimento.

Não estamos negando a dimensão conceitual, que se articula com as dimensões procedimentais e atitudinais na Educação Física, mas propondo a valorização também da

\footnotetext{
${ }^{8}$ Nome fictício de um aluno da $7^{a}$ série de uma escola da rede pública estadual.
} 
experiência e do saber da experiência como possibilidade de conhecer, fazer e conhecer com esse fazer. A experiência/vivência com o movimento humano/práticas corporais gera um tipo de conhecimento insubstituível, que não pode ser apenas descrito, mas provado (no sentido de experienciar), mesmo tendo consciência que, ao tematizá-los, se elabore um conhecimento conceitual, atendendo a um dos principais propósitos da educação escolar. Nas palavras de Fensterseifer e González (2010), isso significa

que os saberes produzidos pela experiência das manifestações corporais não podem ser substituídos pela reflexão conceitual sobre elas, da mesma forma que os conhecimentos originados na vivência da prática não substituem as ferramentas cognitivas fornecidas pelos conceitos. Esses saberes se complementam e, por isso, exigem ser tratados de forma específica e articulados numa proposta de EF escolar (p. 17-18).

Acreditamos estar conseguindo articular, em nosso "Mapa de Trabalho", pelo menos em parte, os saberes produzidos na/pela experiência de movimento/práticas corporais com a dimensão conceitual nas aulas de Educação Física. Para exemplificar essa afirmação, podemos citar duas experiências de nossa ação interventiva:

a) ao tratarmos do tema "a passagem do jogo ao esporte institucionalizado", relembramos aos alunos "que todo esporte já foi jogo um dia", referindo-nos às concepções históricas dessas manifestações corporais. O jogo possui um caráter de flexibilização de suas regras, com outros sentidos e significados, podendo ser adaptado de acordo com a realidade material em que se realiza. Ao ser institucionalizado, porém, assume características próprias da instituição que o cria, atendendo aos interesses desta, atribuindo outros sentidos, universalizando suas regras, com um caráter mais rígido, exigindo espaços formalizados para a sua realização (esporte institucionalizado). Experimentamos o jogo e o esporte, tanto no plano procedimental, quanto no plano conceitual, atribuindo-lhes outros sentidos, reinventando-os para atingir um dos propósitos da instituição escolar e, muitas vezes, criamos o esporte "da" escola;

b) em outra situação de ensino, ao tratarmos dos temas/conteúdos que compõem o universo das manifestações da cultura corporal de movimento, tentamos articular/elaborar possibilidades de movimento/práticas corporais, tanto no plano conceitual (construindo regras, formas de jogar/pontuar/avaliar/apreciar), quanto no plano procedimental 
(empregando técnicas e estratégias para a sua realização). Após essa experiência, redefinimos, analisamos, reavaliamos, discutimos, juntamente com os alunos, se as atividades elaboradas atendem a dimensão conceitual e se esta atende à dimensão procedimental. Depois, as reelaboramos e nos submetemos a uma nova "experimentação". Nessa forma de experienciar sentidos outros para a Educação Física, não esquecemos as estruturas e representações sociais que atravessam esse universo do movimento humano/ práticas corporais (FENSTERSEIFER; GONZÁLEZ, 2010).

A experiência proporcionada pela construção e reconstrução constantes de nosso "Mapa de Trabalho" ou "Programa Mínimo" para a Educação Física, nos possibilita ter um projeto "próprio" com autoria docente, que vai muito além de um plano de atividades esportivas e contribui para legitimar a Educação Física como componente curricular, juntamente com as demais disciplinas na instituição escolar. Várias experiências como a nossa têm sido realizadas, por professores e professoras de escolas públicas (FENSTERSEIFER; GONZÁLEZ, 2007), e discutidas no âmbito da Educação e da Educação Física (BRACHT; CAPARROZ, 2007), no intuito de contribuir para a consolidação de uma nova forma de pensar a Educação Física e suas contribuições específicas para atingir alguns dos propósitos da escola enquanto instituição republicana. É preciso salientar que essas experiências, materializadas em propostas para a Educação Física, necessitam encontrar mais espaços para a sua socialização (seminários, encontros, grupos de ação-reflexão-ação...) e, também, apoio pedagógico das instituições em que se realizam.

A socialização dessas diferentes propostas pode nos auxiliar a estruturar/complementar nossos "próprios" programas para a Educação Física através do diálogo e da reflexão coletiva. Para exemplificar essa afirmação, podemos destacar uma de nossas limitações em sistematizar os temas/conteúdos de aprendizagem em criticidade, complexidade e continuidade nas aulas de Educação Física. Dentre esses fatores limitantes, citamos: a troca constante de turmas (muitas vezes de escola), que não nos permite dar continuidade (sequência) ao trabalho nas diferentes séries; a não participação coletiva na construção/ implementação de uma proposta comum de trabalho; e a falta de uma proposta institucional legítima que sirva de referência para as aulas de Educação Física. 
No diálogo constante que temos feito entre nossa ação interventiva ("prática") com as obras ("teoria") que tratam sobre o tema (Educação Física escolar), encontramos referências para refazer e repensar constantemente nosso programa mínimo e auxiliar em sua sistematização (sempre inacabada), produzindo algumas possíveis "soluções" para os fatores limitantes que dificultam sua consolidação. Uma dessas referências é o trabalho dos professores Fernando Jaime González, Alex Branco Fraga e seus colaboradores (2009), que se constitui na elaboração de uma proposta curricular para o Estado do Rio Grande do Sul, contemplando especialmente as séries finais do Ensino Fundamental ( $5^{\mathrm{a}}$ a $8^{\mathrm{a}}$ séries $)$, e todo o Ensino Médio ( $1^{\circ}$ ao $3^{\circ}$ ano). Esse referencial apresenta um programa que tenta explicitar os saberes considerados fundamentais para a Educação Física, com uma fundamentação nas teorias críticas da Educação e da Educação Física e a sistematização de um conjunto de competências e conteúdos que esse componente curricular deveria tratar em cada série. Temos nos apropriado de alguns dos elementos constituintes dessa proposta para reinventar a "nossa", em especial quando nos auxiliam a pensar a progressão estruturada dos conteúdos a serem abordados ao longo dos anos escolares e o tempo pedagógico destinado à abordagem de tais conteúdos (MARTINY; FLORÊNCIO; GOMES-DA-SILVA; 2011). Mas é preciso ter cuidado ao tentar universalizar essa proposta "transferindo-a" para o contexto de trabalho, pois os próprios autores chamam a atenção de que esta representa um "ponto de apoio" para os professores, os quais precisam (re)elaborar e (re)inventar em seus contextos as proposições que julgarem mais adequadas. Retomando Gadamer (2008), enfatizamos que a experiência só se atualiza nas observações (vivências) individuais, pois não podemos conhecê-la numa universalidade prévia.

Tememos, porém, que esse referencial curricular nem tenha sido encaminhado às escolas públicas estaduais, pois essa proposta materializou-se como uma política de governo e não como uma política de Estado ${ }^{9}$. Como outros tantos referenciais, advertimos que esse referencial corre o risco de ser estigmatizado antes mesmo de uma análise mais aprofundada de seu conteúdo, o que só seria possível ao conhecê-lo e, em julgando pertinente, vivenciá-lo. De nossa parte, acreditamos que esse material poderia nos auxiliar a consolidar novas proposições para a Educação Física como componente curricular. Para

${ }^{9}$ Visitamos algumas escolas públicas estaduais de nossa região e não encontramos nenhum exemplar dos referenciais curriculares do Estado do Rio Grande do Sul para a Educação Física. 
tanto, seria fundamental que o professor o adotasse, juntamente com outras referências didático-pedagógicas, de forma autônoma, não sendo adotado por esta ou qualquer outra proposição, apontando fundamentadamente os acertos e limites de toda proposição humana.

\section{Considerações finais}

Na constante reformulação de nosso Mapa de trabalho e/ou “programa mínimo", estamos em um constante movimento de pensar o sendo da Educação Física no contexto escolar. Esse inacabamento nos oportuniza uma autoria docente e nos autoriza a experimentar/ construir algumas respostas, sempre parciais, para os desafios que hoje se colocam para a Educação Física escolar, através de nossa ação interventiva e reflexiva.

Um desses desafios, como já mencionamos anteriormente, é o de nos entregarmos à experiência do diálogo como alguém que não sabe tudo. Essa postura dialógica nos compromete com o coletivo e nos conduz a respeitar e a reconhecer no outro ${ }^{10}$, no diferente de nós mesmos, "um horizonte inesgotável de sentido", capaz de fazer-nos repensar nossas supostas certezas "como que um questionamento permanente que quer ser levado a sério, tanto em termos teóricos, quanto em termos práticos" (FLICKINGER, 2010, p. 43).

${ }^{10} \mathrm{O}$ outro aqui mencionado nem sempre é uma pessoa concreta (aluno ou professor), mas se materializa também nas obras humanas (textos), na linguagem, na história, na tradição. 


\section{REFERÊNCIAS}

ARENDT, Hannah. A crise na educação. In: ARENDT, H. Entre o passado e o futuro. São Paulo: Perspectiva, 2002.

BETTI, Mauro. O que a semiótica inspira ao ensino da educação física. Discorpo, São Paulo, n.3, p.25-45, 1994.

Por uma teoria da prática. Motus Corporis, Rio de Janeiro, v. 3, n. 2, p. 73127, 1996.

BRACHT, Valter. Educação física \& ciência: cenas de um casamento (in)feliz. 2. ed. ljuí: Ed. Unijuí, 2003.

. Cultura corporal, cultura de movimento ou cultura corporal de movimento? Recife, fevereiro, 2004 (mímeo).

BRACHT, Valter; CAPARROZ, Francisco Eduardo. O tempo e o lugar de uma didática da educação física. In: Revista Brasileira de Ciências do Esporte. Campinas, v. 28, n. 2, p. 21-37, jan. 2007.

BRASIL. Parâmetros Curriculares Nacionais: educação física. Brasília: Secretaria de Educação Fundamental, 1998.

COLETIVO DE AUTORES. Metodologia do ensino da educação física. São Paulo: Cortez, 1992.

DARIDO, Soraya Cristina. Os conteúdos da educação física escolar: influências, tendências, dificuldades e possibilidades. In: Perspectivas em Educação Física Escolar. Niterói, v. 2, n. 1 (suplemento), 2001. p. 5-25.

FENSTERSEIFER, Paulo Evaldo; GONZÁLEZ, Fernando Jaime. Educação física escolar: a difícil e incontornável relação teoria e prática. Motrivivência, Florianópolis, ano XIX, n. 28, p. 27-37, jul./2007.

. Entre o "não mais" e o "ainda não": pensando saídas do não-lugar da ef escolar

I. Cadernos de Formação RBCE, p. 9-24, set. 2009.

. Entre o "não mais" e o "ainda não": pensando saídas do não lugar da ef escolar

II. Cadernos de Formação RBCE, p. 10-21, mar. 2010. 
FLICKINGER, Hans-Georg. A caminho de uma pedagogia hermenêutica. Campinas, SP: Autores Associados, 2010. (Coleção Educação Contemporânea).

GADAMER, Hans-Georg. Verdade e método I: traços fundamentais de uma hermenêutica filosófica. Tradução de Flávio Paulo Meurer; revisão da tradução de Enio Paulo Giachini. 10. ed. Petrópolis, RJ: Vozes, 2008.

GONZÁLEZ, Fernando Jaime. A classificação dos esportes. Texto de referência utilizado com os alunos de graduação do curso de Educação Física - Unijuí, 2003 (mímeo). Projeto Curricular em educação física: o esporte como conteúdo escolar. In: REZER, R. (Org.): O fenômeno esportivo: ensaio crítico-reflexivos. Chapecó: Argos, 2006. p. 69-109.

GONZÁLEZ, Fernando Jaime; FRAGA, Alex Branco. Referencial Curricular de Educação Física. In: RIO GRANDE DO SUL. Secretaria de Estado da Educação. Departamento Pedagógico. (Org.). Referenciais Curriculares do Estado do Rio Grande do Sul: Linguagens, Códigos e suas Tecnologias. Porto Alegre: SE/DP, 2009, v. 2, p. 111-181.

Afazeres da Educação Física na escola: planejar, ensinar, partilhar. Erechim: Edelbra, 2012.

HERMANN, Nadja. Hermenêutica e educação. Rio de Janeiro: DP\&A, 2002.

KUNZ, Elenor. Transformação didático-pedagógica do esporte. 4. ed. ljuí: Ed. Unijuí, 2000.

MARQUES, Mario Osório. Os paradigmas da educação. In: Revista Brasileira de Estudos Pedagógicos, v. 73, n. 175, p. 547-565, set./dez. 1992.

MARTINY, Luis E.; FLORÊNCIO, Samara Q. N.; GOMES-DA-SILVA, Pierre N. O referencial curricular da educação física do Estado do Rio Grande do Sul. Pensar a Prática, Goiânia, v. 14, n. 1, p. 1-14, jan./abr. 2011.

PÉREZ GÓMEZ, A. I. As funções sociais da escola: da reprodução à reconstrução crítica do conhecimento e da experiência. In: PÉREZ GÓMEZ, A. I.; SACRISTÁN, J. G. Compreender e transformar o ensino. 4. ed. Porto Alegre: Artmed, 1998, p. 13-26.

SACRISTÁN, J. Gimeno. O currículo: uma reflexão sobre a prática. Porto Alegre: Artmed, 2000. 


\title{
THE RELATIOSHIP THEORY-PRACTICE IN SCHOOL PHYSICAL EDUCATION: DEPLOYMENT TO THINK A “MINIMUM PROGRAM"
}

\begin{abstract}
The goal of this paper is to reflect on the difficult and complex relationship between theory and practice in physical education. In the background, brings elements of some propositions made in public schools, materialized in an attempt to build a work plan proposal or a "minimum program" for Physical Education for beyond a simple "physical exercise", envisaging the knowledge construction to be developed over the school year in terms of criticality, complexity and continuity. For this, we consider the relation between theory and practice, precondition to think physical education in the school context and value the experience and experience knowledge as a way to know, to do and to learn. This experience takes place in the constant and ever-renewed dialogue with the action interventional, other teachers and publications on the subject. We conclude that construction of this proposal allows us to (re)build and reinvent our profession with authorship, "experiencing" the chances of finding some answers for challenges that arise today for Physical Education, through our interventional and reflective action.
\end{abstract}

Keywords: Physical education. School context. Experience. Work plan proposal. 


\section{LA RELACIÓN TEORÍA-PRÁCTICA EN LA EDUCACION FÍSICA ESCOLAR: DESDOBLAMIENTOS PARA PENSAR UN “PROGRAMA MINIMO”}

RESUMEN: El propósito de este artículo es reflexionar acerca de la difícil e compleja relación teoría-práctica en la Educación Física. Como tela de fondo, aporta elementos de algunas proposiciones realizadas en escuelas públicas, materializadas en un intento de construir una propuesta de trabajo o "programa mínimo" para la Educación Física, más allá de un simple "hacer ejercicio", vislumbrando la construcción de un saber que se desarrolla a lo largo de los años escolares en términos de criticidad, la complejidad y la continuidad. Para esto, consideramos la relación teoría-práctica condición indispensable para pensar la Educación Física en el contexto escolar y valorar la experiencia y el saber de la experiencia como una forma de conocer, hacer y conocer con este saber. Esta experiencia ocurre en lo diálogo constante y siempre renovado con la intervención, otros maestros y las obras que tienen que ver con el tema. Llegamos a la conclusión de que la construcción de esta propuesta nos permite (re) construir y reinventar nuestra profesión con autoría, "experimentando" las posibilidades de encontrar algunas respuestas para los desafíos que actualmente son colocados para la Educación Física, a través de nuestra intervención y reflexión.

Palabras-clave: Educación Física. Contexto escolar. Experiencia. Propuesta de trabajo. 